\title{
DINHEIRO, EMOÇÃO E AGÊNCIA: \\ UMA ETNOGRAFIA NO MERCADO FUNERÁRIO DE PORTO ALEGRE
}

Marcos Freire de Andrade Neves

Arlei Sander Damo

\begin{abstract}
É uma odisseia que começou dois séculos atrás. O termo "undertaker" nasceu nos anos 1800, quando fazendeiros abastados descobriram que, por uma taxa, alguém estava disposto a cuidar dos seus mortos.
\end{abstract}

Robert D. Webster, Does this mean you'll see me naked? (2011)

\section{Introdução}

"Pois é preciso que a Morte, em uma sociedade, esteja em algum lugar; se não está mais (ou está menos) no religioso, deve estar em outra parte", escreveu Roland Barthes ao investigar a possibilidade de a fotografia ser pensada nos moldes de uma morte "assimbólica", pois alheia à religião e ao ritual (1984:137-138). Se aceitarmos a premissa de Barthes e partirmos à procura do lugar da morte, deveremos considerar a possibilidade de acabar por encontrar não um local ou artefato específicos - como cemitério ou fotografia - mas sim um processo tecido por múltiplos circuitos - como, por exemplo, circuitos de mercado e burocrático - performados por diferentes mediações institucionais - funerárias, cemitérios, cartórios e, no caso específico de Porto Alegre, a Central de Atendimento Funerário, dentre outras. A este conjunto extenso e diversificado de circuitos, que entrecruzam pessoas (vivas e mortas), coisas e lugares, chamamos de complexo funerário ${ }^{1}$ — algo efetivamente amplo e heterodoxo que performa a Morte.

Este complexo é dinâmico, gerando articulações e arranjos concretos que variam de acordo com diferentes épocas e lugares. Quando pensado em uma história de longa duração, aquilo que chamamos de circuito de mercado funerário apresenta-se como algo relativamente novo, característico de sociedades bastante mercadologizadas. Trata-se de contextos nos quais o empreendimento econômico é socialmente consentido - e 
até mesmo regrado pelo Estado - e financeiramente viável, o que ocorre com mais frequência em locais muito povoados onde a morte se apresenta como uma rotina quantitativamente estimável. Cumpridas tais exigências, como no caso etnografado, ${ }^{2}$ é frequente que as agências funerárias sejam encarregadas de um papel destacado, sendo responsáveis por estabelecer as múltiplas mediações exigidas e/ou necessárias para dar aos mortos uma "destinação final".

A atuação das funerárias e dos empreendimentos de destinação final, como cemitérios e crematórios, tende a ser amplamente regulada por normas e legislações específicas. Segundo o Art. 30 da Constituição Federal de 1988, compete aos municípios legislar e organizar serviços públicos "sob regime de concessão ou permissão, [...] de interesse local [...] que tem caráter essencial". ${ }^{3}$ Inscritos nesse registro, os serviços funerários são de competência municipal e assumem contornos diferenciados em cada contexto local. Não deixou de ser uma surpresa a descoberta, realizada no princípio do trabalho de campo, de que o circuito do mercado funerário porto-alegrense - cidade onde foi realizada a maior parte das incursões de campo, mas não a única possuía uma dinâmica muito singular, tanto em termos de articulação institucional quanto no seu modus operandi.

Como parte do circuito de mercado funerário local destinado à administração privada - como é o caso de empresas funerárias, cemitérios e crematórios - uma ampla gama de regulações técnicas e burocráticas coexiste com a possibilidade de o consumidor escolher a empresa de sua preferência e um sem-número de serviços e produtos diversos. A concessão ao setor privado, por meio de permissão pública, não é regra no Brasil. Um ponto de contraste pode ser observado na cidade de São Paulo, onde o serviço funerário é de competência exclusiva do SFMSP (Serviço Funerário do Município de São Paulo), órgão responsável pela administração de 11 agências funerárias, 22 cemitérios, 18 espaços para velórios e um crematório. Constitui-se, assim, a maior autarquia do município, com cerca de 2 mil servidores. ${ }^{4}$

A noção de circuito, inspirada em Zelizer (2005), passa a ser fundamental para esclarecer o local da etnografia e o tipo de performação analisada: ela permite integrar as diferentes mediações a que são sujeitos os mortos, configurando um processo - ou percurso - compreendido entre a declaração de óbito (um ato médico) e a destinação final do corpo. ${ }^{5}$ A noção de circuito será usada no plural, objetivando captar as especificidades de diferentes percursos possíveis, devendo-se ressaltar que nem todos são mediados pelas empresas funerárias. Cadáveres destinados à pesquisa, por exemplo, movimentam-se no espectro de um circuito particular, tanto do ponto de 
vista legal quanto moral e econômico. Por mobilizar diferentes mediações, como universidades e, em geral, Departamento Médico Legal, tais corpos permanecem à margem do circuito do mercado funerário convencional, embora estejam sujeitos a uma economia à base da dádiva, do escambo ou da clandestinidade. ${ }^{6}$ Indigentes ou cadáveres de famílias pobres, cuja destinação final fica sob responsabilidade do Estado, também mobilizam um conjunto de mediações específicas e, dessa forma, acabam transitando por um circuito próprio. Um circuito que possui similaridades e, por vezes, compartilha mediações com outros, mas tem uma lógica de funcionamento distinta: nos casos em que o Estado terceiriza esses serviços, os familiares estão ausentes ou não dispõem de dinheiro, reduzindo a negociação do preço dos serviços, objeto por excelência deste artigo.

São circuitos que não representam fronteiras rígidas entre os caminhos que os trilham, mas sim trajetos que muitas vezes se entrelaçam e compartilham mediações. Por ocupar um lugar de destaque nas mediações, ao menos no caso de Porto Alegre, as empresas funerárias - que bem poderiam ser tratadas como empresas privadas quaisquer - têm um lugar de destaque no circuito do mercado funerário e, por isso mesmo, constituem um espaço privilegiado para investigar a "performação da morte". O termo, apropriado de Callon (1998), contribui para circunscrever a etnografia, pois a maneira como o mercado performa a morte - e certas funerárias em particular constitui uma forma de agenciamento que se revela não apenas nos bens e serviços ofertados, mas também nas estratégias de negociação empreendidas, no tratamento dado aos clientes, no ambiente no qual são realizadas as negociações e os serviços, e assim por diante. ${ }^{7}$ Dizer que o mercado funerário performa a morte não implica dizer que ele a reduza a uma transação econômica (ou a um conjunto delas), mas sim que ele introduz uma dada perspectiva. Em todo caso, pretendemos mostrar como há não apenas uma "mercadorização" da morte, mas uma modalidade sui generis, seja porque a morte não é um evento qualquer, ou porque as funerárias nas quais o trabalho de campo foi realizado procuram se diferenciar do que seria, segundo elas próprias, um mercado estigmatizado.

Embora haja uma bibliografia extensa tratando da morte no espectro da antropologia, ${ }^{8}$ são escassas as abordagens realizadas pelo viés da antropologia econômica. Ainda assim poder-se-ia listar uma série extensa de trabalhos, sobretudo nas etnografias clássicas, que tratam de temas correlatos, como é o caso das heranças, uma questão que mescla economia, direito e parentesco. Nosso recorte é mais restrito, pois enfoca as negociações realizadas no interior de funerárias envolvendo a venda de bens e serviços mobilizados para os cerimoniais e a destinação final dos mortos. 
Ao longo de um ano de pesquisa empírica, entre 2012 e 2013, uma funerária ocupou lugar central. Nela, trabalhos de campo foram realizados cerca de duas vezes por semana. Outras duas funerárias também foram pesquisadas, embora com visitas menos frequentes. Incluem-se ainda quatro cemitérios em Porto Alegre e região metropolitana, onde realizamos entrevistas com seus funcionários, observamos eventos específicos e acompanhamos o trabalho dos agentes funerários. Todas as empresas envolvidas no trabalho empírico abriram as suas portas através de um contato preliminar, seguido de conversas presenciais nas quais o intuito do projeto foi apresentado às suas direções e, em seguida, aos funcionários que nos receberiam e viriam a se tornar os nossos principais e mais frequentes interlocutores.

Em algumas empresas, as direções solicitavam aviso prévio acerca das datas de trabalho de campo, de modo a garantir a disponibilidade de funcionários que seriam responsáveis por apresentar os espaços físicos das empresas e a falar em seus nomes. Entretanto, em uma funerária este não foi o caso. Seu espaço ficou permanentemente disponível para observações participantes, sem imposição de avisos prévios, turnos ou alcance de qualquer sorte. Seus arquivos internos nos foram disponibilizados, tínhamos acesso aos seus funcionários e, inclusive, éramos convidados para acompanhá-los em todos os seus serviços, sejam os burocráticos, os técnicos ou de negociação. Nesta funerária central para a dinâmica da pesquisa

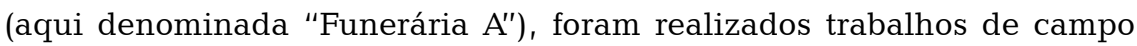
em diferentes turnos, em especial durante as manhãs e tardes - o turno noturno também foi observado em algumas ocasiões, porém com menos frequência. Por estar aberta ininterruptamente todos os dias da semana, foram realizadas incursões empíricas tanto em dias de semana quanto em sábados, domingos e feriados. A possibilidade de ter acesso irrestrito ao seu pessoal, ao espaço físico e aos serviços identificou no ambiente da Funerária A uma força motriz essencial ao trânsito entre os diferentes espaços institucionais do complexo funerário como um todo, e do circuito do mercado funerário em particular.

Para este artigo, no entanto, circunscrevemos o olhar à negociação em torno do preço dos bens e serviços funerários, pois se trata de um momento dramático no qual se tensionam as relações entre dinheiro e afeto. O texto tem por objetivo não somente mostrar a especificidade dessas negociações, mas também apresentar como as mediações que performam o circuito no qual a etnografia se focou buscam constituir um modelo de "mercado transparente". Um dos dilemas capitais dessa negociação é equilibrar a delicada e instável relação entre uma economia financeira e outra afetiva, entre o lucro desejado pelos vendedores e a susceptibilidade emocional dos 
compradores, entre um mercado moralmente estigmatizado e outro que se pretende legítimo. A etnografia nos fez atentar para as especificidades das negociações, a performance dos agentes funerários, as interdições e, sobretudo, a complexidade da relação entre dinheiro e afetos. Isto inclui, entre outras coisas, a agência da pessoa morta e do "espírito de orelha" designação atribuída pelos agentes funerários a um papel, com frequência desempenhado por um "familiar distante" que vigia as negociações para impedir que o "familiar próximo", geralmente mais afetado emocionalmente, realize gastos inadequados.

\section{A funerária que não gostaria de ser uma funerária}

Com a sugestão de que "o mercado se trata de algo novo, que atrai a curiosidade e deve ser conhecido", João, ${ }^{9}$ coordenador operacional da Funerária $\mathrm{A}$, consentiu na realização da etnografia. A abertura das portas de seu empreendimento - e a confiança com que o fez - diz muito a respeito do que ele pretende com o "algo novo" nesse mercado associado a estigmas de toda ordem. Afora a designação do tipo de empreendimento explícita na fachada do estabelecimento, quase nada em seu interior imediato - em sua recepção decorada com confortáveis sofás, quadros e arranjos de flores artificiais, na qual havia televisão, revistas e jornais à disposição dos clientes - sugeria que se tratava de uma funerária. Somente discretos diplomas de prêmios e certificações específicas do ramo fixados na parede, ou então revistas de segmento como a "Diretor Funerário", asseguravam se tratar de uma funerária.

Luís, responsável pela Funerária B - na qual também foi realizado trabalho de campo - explica que sua funerária foi pensada "de modo a não parecer uma funerária", afinal, o cliente precisa "comprar um produto que não quer, num momento e para alguém que também não quer". Com isto em vista, o atendimento é realizado em duas confortáveis salas, nas quais os responsáveis ficam sentados em um sofá enquanto o agente, próximo a eles, permanece em uma cadeira com suporte para apoiar o computador. Cafés são servidos e, caso o responsável precise descansar ou aguardar por alguns instantes, há um espaço confortavelmente mobiliado com sofá, poltronas, televisão e revistas.

As duas funerárias confluem na ausência de símbolos que remetem a um imaginário comum da morte associado a materialidades específicas, restringindo a exibição de urnas funerárias e produtos afins em um determinado espaço. Com base em uma pesquisa interna realizada pela 
Funerária B, que indicou a escolha da urna como o pior momento para o cliente durante seu período na funerária, o mostruário - ou sala expositora, local onde um exemplar de cada modelo é exposto para que o cliente possa vê-lo e satisfazer suas dúvidas quanto ao produto - ficou restrito a uma sala no andar superior. Embora as portas sejam de vidro, uma pequena recepção com sofás e delimitada por biombos de madeira impede a visão dos produtos por quem está no seu exterior. Característica similar pode ser observada na Funerária $A$, onde as urnas e as roupas funerárias ficam expostas em uma sala contígua à recepção, dela separada por uma longa porta de correr feita de madeira e que somente é aberta em caso de atendimento.

Três são os tipos de atendimentos que a funerária pode realizar: o primeiro deles, "atendimento de complementação", é aquele que tem origem em um serviço já iniciado por outra empresa e que envolve, geralmente, necessidades de traslado para outros municípios do Rio Grande do Sul e Brasil, ou a realização de tanatopraxia. ${ }^{10}$ Por sua vez, o "atendimento plano" envolve um autorizante, ou seja, associações ou empresas de assistência, que contatam a funerária e emitem autorização para iniciar o atendimento de um óbito. Já o "atendimento particular", sem a mediação de planos assistenciais, é aquele em que o familiar ou responsável contrata a funerária diretamente. A Funerária A é composta por funcionários que integram equipes de plantão, garantindo assim o funcionamento ininterrupto da empresa, de acordo com o prescrito na Lei 373/1996, responsável por regular a atuação das funerárias no município. ${ }^{11}$ Há uma diretoria que não acompanha o cotidiano da empresa, mas que deve ser informada periodicamente a respeito dos serviços e na eventualidade de qualquer problema; um coordenador operacional, responsável pelo gerenciamento dos agentes funerários, auxiliares funerários e auxiliares de preparação. ${ }^{12}$

Com uma divisão de tarefas estabelecida, cada funcionário assume uma atribuição específica ao cargo que ocupa. Enquanto a venda e o atendimento aos responsáveis e familiares ficam sob responsabilidade direta dos agentes funerários, são os auxiliares que realizam o recolhimento do corpo, o transporte dos responsáveis e, de maneira geral, o acompanhamento à família. Os preparadores, distantes de qualquer contato com o público externo, conduzem o procedimento de tanatopraxia - se contratado - e necromaquiagem, além de vestirem o corpo, uma dinâmica descrita por Mitford como a transformação "de um cadáver comum em uma bela imagem de memória" (2000:59, tradução nossa). É o forte cheiro de formol, segundo Giovanni, um dos preparadores da Funerária A, uma das razões pelas quais não há interação com os responsáveis e familiares. 


\title{
Recém-chegados ao universo de bens: consumidores e o consumo funerário ${ }^{13}$
}

\begin{abstract}
O que nos leva ao segundo aspecto especial da transação funerária: a quase total ignorância do comprador acerca do que esperar quando ele entra no salão da funerária. O que procurar, o que evitar, o quanto gastar. A indústria funerária estima que um indivíduo médio tem que providenciar um funeral apenas uma vez em quinze anos. O custo de um funeral é a terceira maior despesa, após uma casa e um carro, na vida de uma família americana comum.

Jessica Mitford, The American way of death (2000)
\end{abstract}

Em Porto Alegre o mercado funerário é constituído por duas lógicas distintas, descritas por André, diretor de um grupo com empresas no segmento, nos seguintes termos: a primeira, representada pelo chamado "atendimento imediato", é composta por funerárias, cemitérios e crematórios; a segunda, por sua vez, compreende o sistema previdenciário com foco direcionado "às classes C e D". Conforme argumenta André, o foco previdenciário nas camadas com menor poder aquisitivo se dá pela necessidade de planejar um gasto com o qual todos terão que arcar, à exceção de casos que envolvem doação de corpos para fins de ensino e pesquisa ou aqueles assumidos pelo Estado.

Mencionar as "classes $\mathrm{C}$ e D" não foi à toa. A ideia de classe — ou camada - social opera no mercado funerário através da perspectiva de "poder aquisitivo" ou, mais especificamente, de "público-alvo". Em diálogos transcorridos durante o trabalho de campo, percebe-se que denotar um público-alvo por meio da classificação A-B-C-D configura prática comum e envolve abordagens e estratégias distintas por parte dos estabelecimentos funerários. Segundo Luís, gerente da Funerária B, o empreendimento pelo qual está responsável tem o foco direcionado "a um público A-B através de uma infraestrutura diferenciada", com planos específicos e convênios com categorias profissionais, como a Ordem dos Advogados do Brasil (OAB). Suas duas concorrentes mais próximas são descritas pelo profissional, respectivamente, como mais "popular" e voltada a um "público B-A" (pois não são apenas as letras que informam, mas também a sua ordem).

De forma análoga, empreendimentos de destinação final objetivam diferentes públicos-alvos. Em um deles, localizado na região metropolitana de Porto Alegre, Carla, responsável pelo local, informa que atende, "majoritariamente, o público B-C-D", ao contrário de outro empreendimento da mesma empresa, voltado ao público A. Conquanto ambas as instalações e infraestruturas sejam modernas e similares, "alguns acabamentos e a localização influem no valor final". Em seu turno, o empreendimento com foco 
no "público A" mencionado por Carla não atende a planos "mais populares", pois comercializa outro, voltado "às camadas mais ricas", conforme explica Marta, outra funcionária do empreendimento. Independentemente do público-alvo ou das estratégias relacionadas, o circuito do mercado funerário permanece pouco conhecido do público geral. "Muitos dizem", prossegue André, "que esse é o melhor mercado, porque não tem ninguém pra reclamar depois". "É mentira!", acrescenta. Segundo comenta, esse mercado é altamente pressionado, pois apenas um erro pode ser trágico. "O momento é único, não se pode fazer dois funerais", logo, todos os componentes devem estar à prova de qualquer erro: "É a situação mais pesada emocionalmente que alguém tem, quando se perde uma pessoa".

Felipe, gestor de uma funerária em Porto Alegre, diz que "mercadologicamente falando, [funerária] é um mau negócio". Segundo ele, qualquer novidade é "firula, afinal, um caixão diferente continua sendo um caixão", não havendo muitas possibilidades de diversificação no segmento: "Ou você lida com planos e acaba virando uma seguradora, ou você reconhece suas limitações. Dono, atuando como gerente, mais cinco ou seis funcionários: mais do que isso a empresa não dá lucro e não deveria existir". O circuito do mercado funerário, onde o corpo morto é preparado, velado e sepultado por meio da mediação das funerárias e seus funcionários, é protagonizado pelo ato de consumo resultante da interação entre cliente e profissional. Um consumo atento à urgência da ocasião, com frequência realizado pelo cliente sem que ele tenha qualquer contato prévio com o universo adentrado, sem conhecimento dos procedimentos exigidos e das opções disponibilizadas. Um consumo que deve ser efetivado em um ambiente novo, sob fortes tensões emocionais e estrita limitação temporal para pesquisas de preço.

Pensar o consumo no circuito do mercado funerário é pensá-lo em meio a esse marco de restrições e constrangimentos, uma tendência supostamente oposta ao que se julga ser o consumo. Nas palavras de Campbell, "a atividade fundamental do consumo, portanto, não é a seleção, a compra ou o uso dos produtos, mas a procura pelo prazer imaginativo a que a imagem do produto se empresta, sendo o consumo verdadeiro, em grande parte, um resultante desse hedonismo 'mentalístico'" (2001:130). A proposta do autor consiste em refletir sobre o ato de consumo enquanto uma procura pela satisfação pessoal, uma espécie de consumo hedonista que comporia o que chama de "espírito do consumismo moderno". ${ }^{14}$

Em um primeiro momento, o contexto etnografado sugere um contraponto à tese de Campbell, segundo a qual o consumo estaria vinculado ao anseio pelo "prazer imaginativo". No entanto, olhando de outro ponto de vista, é possível traçar um paralelo, pois embora o disparador deste consumo 
seja indesejado, a apreciação do resultado no seu conjunto não o é (como será exemplificado adiante). Há por parte dos familiares mais próximos do morto, incumbidos da escolha e da aquisição dos bens e serviços funerários, uma clara orientação no sentido de "agradar o ente querido", e o êxito ou fracasso neste empreendimento tende a ser objeto de apreciação dos demais familiares e amigos. Propiciar um "funeral digno" talvez não seja um ato de prazer imaginativo convencional, mas é inegável que, quando exitoso, os familiares que realizaram as negociações e "acertaram" nas escolhas e no preço tendem a expressar uma certa satisfação pelo "dever bem cumprido", uma espécie de eufemismo moral que emoldura, pelo menos nestas circunstâncias, um sentimento estético, cuja expressão pública seria inconveniente para a ocasião. ${ }^{15}$

De outra parte, a viabilidade e a efetividade do consumo funerário agem enquanto porta de entrada para uma das dinâmicas de produção da pessoa morta, ou seja, a produção de um estado específico que coisifica a pessoa morta ao mesmo tempo em que lhe concede vida e capacidade de influir nas negociações acerca de sua destinação final. É a inserção nesse circuito que possibilita o gerenciamento póstumo de memória da pessoa morta nos termos do complexo funerário, por meio de serviços de homenagens e de lápide nomeada em empreendimentos de destinação final. Por se tratar de um acesso a possibilidades de produção da pessoa morta que de outra forma não seria possível, o ato de consumo - bem como a sua recusa - é fator constituinte de um estatuto específico de pessoa post-mortem que reforça a sua agência em meio às negociações no decorrer do circuito.

De todo modo, pensar o consumo funerário a partir da motivação dos consumidores esbarra em algumas dificuldades, sobretudo pelo fato de a motivação ser resultado de desejos e imposições de diferentes ordens. No entanto, pensar o consumo funerário através dos bens que são consumidos amplia as possibilidades de compreensão das lógicas em que o ato está envolto. Segundo Douglas e Isherwood, o "objetivo mais geral do consumidor só pode ser construir um universo inteligível com os bens que escolhe", bens que são "acessórios rituais", pois "o consumo é um processo ritual cuja função primária é dar sentido ao fluxo incompleto dos acontecimentos" (2009:112-113).

Dentre os produtos ofertados pelas empresas funerárias, aquele mais próximo do consumidor - e legalmente exigido para todos os óbitos - é a urna. Protagonista do universo de bens associados a um imaginário comum da morte, a escolha da urna é uma etapa localizada no cerne do circuito do mercado funerário. É ela a responsável pela maior margem de lucro das funerárias e pelo maior dispêndio do consumidor. Se para Douglas e 
Isherwood "o consumo usa os bens para tornar firme e visível um conjunto particular de julgamentos nos processos fluidos de classificar pessoas e eventos" (2009:115), o papel desempenhado pela urna, ao ser consumida em conjunto com os demais produtos e serviços, é o de produzir a pessoa após a morte: uma pessoa que será tecnicamente preparada e nela acondicionada. Somente na urna a pessoa pode ser velada, sepultada e cremada, formando, assim, um conjunto indissociável e necessário para o trilhar do circuito após a etapa referente à empresa funerária. Nesse sentido, a urna contribui para o processo de fabricação da pessoa morta e sinaliza uma demarcação espacial entre vivos e mortos. A urna "fixa significados" (Douglas e Isherwood 2009:112) ao mesmo tempo em que auxilia a sua produção. Não obstante o seu emprego não ser universal, no contexto observado, a ausência da urna em cerimônias fúnebres com certeza geraria estranheza, pois nessas ocasiões ela é tão essencial quanto o corpo. Por esta razão, a escolha da urna, muito embora não seja um ato propriamente hedonista, é um evento capital.

\section{Economia emocional}

Outros diretores funerários admitem terem sido terríveis homens de negócio ao longo dos anos por causa da natureza de confiança de suas empresas. Quando uma família vem a nós em um tempo de desespero, muitos de nós acham difícil abordar finanças. Eu sempre tenho esperança que a família mencione dinheiro primeiramente. Mesmo após três décadas, eu ainda acho desconfortável questionar uma família enlutada sobre como eles vão pagar a conta.

Um velho diretor funerário amigo meu disse uma vez, "as lágrimas secam quando a conta chega".

Robert D. Webster, Does this mean you'll see me naked? (2011)

Era um dia repleto de serviços na funerária. Seis. Caso consideremos uma média de 40 óbitos diários em Porto Alegre, é seguro afirmar que, naquele momento, 15\% deles envolviam a atuação da Funerária A. Um atendimento estava em curso em um dos balcões da funerária, onde profissional e cliente, face a face, negociavam o serviço a ser requisitado: "Quero só ver a facada que você vai me dar", disse a cliente, uma mulher que resolvia os preparativos para o funeral do seu pai. Ela havia ido à funerária na companhia de um primo.

Como o falecido possuía seguro, os termos da apólice foram a ela esclarecidos: a seguradora cobriria $50 \%$ do custo total caso a escolha fosse pelo sepultamento, ou 100\% na preferência pela cremação. Nesse momento, 
o primo que a acompanhava sugeriu a opção menos dispendiosa, ouvindo como resposta: "Tá louco? Meu pai se levanta do túmulo e me estapeia". Convencido, ele olha para o agente funerário e para a familiar responsável e sentencia: "Bota uns algodões nele e deixa o velho bonito. A gente faz uma vaquinha, já viu alguém ficar sem ser enterrado?".

Com o atendimento se aproximando do fim, desço em direção ao laboratório de tanatopraxia, onde o coordenador operacional da funerária, o responsável pelas preparações e alguns trabalhadores da obra que estava sendo feita nos fundos do local conversavam em meio a duas urnas ocupadas por corpos já preparados. Era uma senhora idosa e um homem, com cerca de 40 anos, prontos para serem transferidos aos empreendimentos de destinação final contratados. Na conversa, o clima era de descontração e Eduardo - um dos preparadores - comentava: "O negócio é fazer piada agora, porque quando chegar a nossa hora a gente vai ser motivo de chacota dos outros". Durante a conversa, Marcelo, agente funerário que havia acabado de conduzir o atendimento descrito, se junta ao grupo e relata a conclusão da cliente sobre a sua atuação. Ela teria dito, nas palavras de Marcelo: "Gostei de ti, tu é claro, direto, me cobrou".

É manifesto que a decisão de consumo não foi tomada com base apenas em uma racionalidade econômica de custo e benefício, cálculo que justificaria a opção pela cremação sem dispêndios adicionais, e não pelo sepultamento, escolha que implicou complementação do pagamento. Ao longo da interação entre agente funerário e familiares, havia dois polos vocais no lado do consumidor: a familiar responsável, filha do falecido, e o outro familiar, seu sobrinho. Uma vez apresentadas as alternativas e os respectivos preços pelo agente funerário, a escolha em prol do melhor custo-benefício - destinação final sem custos extras ao consumidor - foi a sugestão do sobrinho à responsável, que rapidamente a rechaçou com base em um argumento moral, um provável desejo manifestado em vida pelo falecido.

Logo, quatro foram os papéis e os posicionamentos ao longo dessa negociação: o agente funerário, responsável pelo esclarecimento de questões relacionadas à apólice de seguro e pela exposição das opções de produtos disponíveis para a aquisição na funerária; a filha, sobre quem recaiu a responsabilidade da última palavra no ato de compra e foi propositora de um argumento que contrariou um cálculo meramente econômico; o sobrinho, para quem o custo-benefício deveria ser considerado; e o falecido, cuja manifestação em vida de sua vontade, em conjunto com sua presença mnêmica ao longo de todo o processo e, em especial, durante o atendimento, estabeleceu um ponto de referência entre o que deveria ser feito - o sepultamento, que ele aprovaria - e o que deveria ser evitado — a cremação. Se considerarmos que 
os familiares não tinham, eles próprios, preferência clara entre cremação ou sepultamento, preferindo a primeira porque seria a mais barata mas optando pela segunda por ser a orientação do falecido, pode-se notar a agência deste no ato de negociação. Sua vontade manifesta em vida estabeleceu uma fronteira moral e econômica no domínio das possibilidades de destinação final.

Como se pode notar a partir da negociação aqui descrita - um caso paradigmático que contempla diversas negociações acompanhadas durante o trabalho de campo - estamos diante de um evento que extrapola, em vários aspectos, as negociações convencionais, razão pela qual se poderia situá-lo no espectro de um "mercado de singularidades", um domínio em que se sobressai a dimensão qualitativa tanto dos produtos quanto das negociações (Karpik 2007). ${ }^{16}$ Acerca da singularidade da negociação funerária, ao menos dois aspectos devem ser destacados. $\mathrm{O}$ primeiro diz respeito à mistura de dinheiro e afeto, como já ressaltamos desde o início do texto e, por esta razão, talvez seja o mais evidente. Um segundo aspecto aborda os papéis desempenhados no decurso da negociação. Neste caso, destacam-se, além do agente funerário, a agência da pessoa morta, cujas vontades são manifestas através de um familiar próximo, alguém que partilha sua intimidade e está autorizado a realizar escolhas minuciosas - o tipo de urna e de flores, as músicas para o cerimonial etc. Ademais, há um quarto agente, representado por um familiar distante, um amigo, ou até mesmo um familiar próximo, porém com menos intimidade e, supostamente, menos afetado emocionalmente.

Por se tratar de uma negociação, todos os partícipes estão aptos a influenciar direta ou indiretamente, o que dificulta a situação à medida que novos sujeitos são a ela incorporados. Raros são os atendimentos em que apenas o responsável se ocupa dos trâmites funerários, pois é frequente a presença de um familiar ou amigo em sua companhia. Segundo Paulo, auxiliar funerário da empresa A, há um termo "de quem é do ramo" para aqueles que acompanham os responsáveis durante o atendimento: "espírito de orelha". O "espírito de orelha" pode influenciar na escolha, aumentando ("ainda que raramente") ou diminuindo o preço do pacote a ser vendido. Como no caso anteriormente descrito, o sobrinho agiu enquanto "espírito de orelha" ao tentar influenciar a escolha da filha do morto na direção de um pacote de serviços menos custoso, em detrimento da opinião do falecido, verbalizada por sua filha na forma de um argumento moral e emocional.

Na medida em que desejamos focar nos arranjos e nas tensões entre dinheiro e afetos, reforçamos o que nos parece ser a estrutura da negociação, que envolve não apenas quatro agentes, mas papéis relativamente bem estabelecidos: embora as performances possam apresentar variações, os quatro 
papéis tendem a ser desempenhados com certa regularidade e poderiam ser representados através de um diagrama simples com dois eixos que entrecruzam duas modalidades de negociações: o horizontal, onde prepondera a lógica de uma economia propriamente econômica, e o vertical, onde se sobressai uma economia moral e afetiva. É importante sinalizar, para todos os efeitos, a presença do "espírito de orelha" e o papel que ele desempenha nesta estrutura, qual seja, o de responsável pelo equilíbrio do negócio.

\section{Figura 1 - Diagrama}

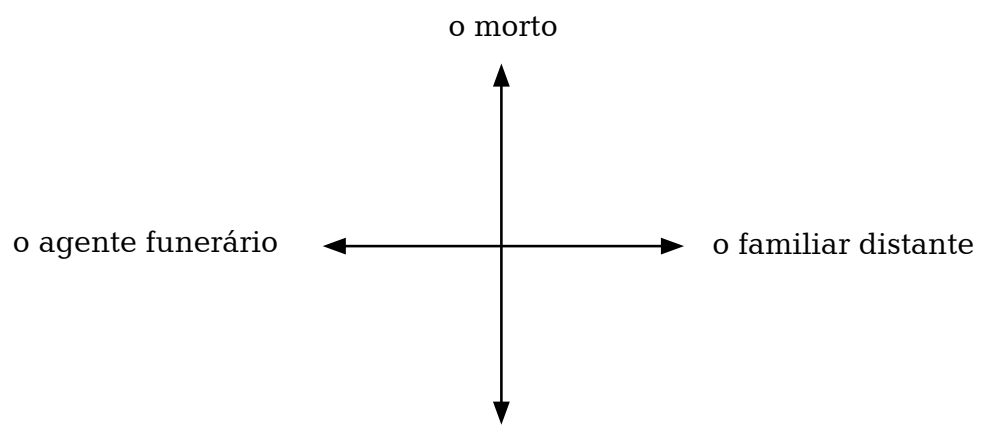

o familiar próximo

O morto é o agente que ativa a negociação, mas sua agência é indireta, devendo ser representada pelo "familiar próximo". Bem representar um morto não implica necessariamente fazer as escolhas mais dispendiosas, mas sim as mais adequadas, razão pela qual é exigida certa intimidade para o exercício deste papel. E havendo intimidade, supõe-se que haja afetação, o que torna este sujeito vulnerável à negociação monetária — pelo menos em tese. Em um mercado tão singular, em que as mercadorias podem ter variações de preço significativas, por vezes acima de $100 \%$, sem que o leigo perceba as razões que as influenciam, é possível agradar o morto com quantias muito desiguais. Por isso mesmo o "espírito de orelha" é fundamental.

O agente funerário está ali para realizar uma "boa venda", isto é, uma venda que seja dispendiosa, mas não além das possibilidades e do senso de justiça dos clientes, pois isto poderia comprometer a imagem da funerária um tipo de preocupação que acompanha sobretudo aquelas bem estabelecidas no ramo. Esta mesma premissa pode ser observada concretamente, em detalhes quase microscópicos. Em tese, a ausência do "familiar distante" seria o ideal para o agente funerário, pois assim a negociação de preço ficaria desequilibrada em seu favor. Ele certamente não aprecia um "espírito 
de orelha" que sugere gastar o mínimo quando o morto ou seus familiares poderiam realizar um funeral conspícuo. Por outro lado, se pensarmos na lógica do negócio como um todo, e não apenas em uma negociação pontual, o melhor a fazer é agradar os clientes - objetivo que conta, seguidamente, com orientação de consultorias de marketing especializadas. O "espírito de orelha" passaria a ser, por esta razão, uma presença desejada em decorrência do equilíbrio que proporciona e, sobretudo, por avalizar eticamente a negociação. João e Marcelo relatam a história de uma família que, inclinada a comprar uma urna de $\mathrm{R} \$ 13.000$, foi surpreendida pelo genro da falecida: "ela vai ser cremada, compra um caixão mais barato e doa o dinheiro para caridade". "O genro acabou com nosso serviço", conclui João.

Em outra ocasião, na Funerária A, que me foi relatada posteriormente, realizou-se o atendimento de uma senhora que em vida havia se manifestado por cremação e desejado ser velada em urna fechada. Após a preparação do corpo e o seu deslocamento para o local do velório, seus familiares ficaram impressionados com o resultado da tanatopraxia, do arranjo das flores, enfim, da harmonia do conjunto. Suas filhas manifestaram, então, o desejo de manter a urna aberta, sendo que esta havia sido adquirida com a recomendação expressa de que o tampo tivesse abertura facial, a única parte que deveria permanecer à mostra segundo a vontade da falecida. Diante do impasse, fez-se um teste, no próprio local do velório, antes de o mesmo ser aberto ao público. Foi consenso entre a família que, com o tampo fechado, ressaltava-se o cenário da morte - fechado, sombrio, triste etc. O que poderia ser um dilema entre a vontade da falecida e o gosto dos familiares foi rapidamente resolvido, com o argumento de que ela desejara ser bem apresentada para a ocasião e por esta razão imaginara que a melhor maneira seria manter a urna fechada, o que não se comprovava no teste. Como argumentou uma das filhas: "Eu garanto, eu não tenho dúvidas: nesta circunstância, ela iria preferir o caixão aberto". E completou: "O pedido dela está sendo contrariado, mas não as motivações que estão na origem. Ela queria mesmo era não parecer uma morta!". Vale acrescentar: as filhas retocaram a maquiagem, colocaram uma echarpe e ocultaram as mãos, com o que lhes pareceu realizar o desejo da mãe.

Em certa ocasião, o agente funerário João, muito animado, justificou sua excitação por ter sido contratado para um "serviço bom": R\$23.000. O óbito era de uma mulher, advogada, e a funerária foi acionada pelo viúvo por meio da recomendação de um empresário que já havia sido cliente da empresa. João brinca que forma com Marcelo uma "dupla dinâmica": João conduz a parte inicial do atendimento, informando todas as opções disponíveis de serviço e oferecendo água e café ao cliente, porém, na hora de informá-los sobre o preço, é Marcelo quem assume o atendimento. 
"Vou te dizer para que tu entendas como funciona a morte", diz João ao comentar o "serviço bom" que acabara de concluir. "Se a mulher estivesse no hospital, se eles fossem se preparando, não teriam escolhido um serviço tão caro". Diante da minha indagação, João conclui: "Por causa da fragilidade emocional". O óbito que originou o serviço mencionado foi repentino, inesperado, e o corpo da falecida foi encontrado em casa pelo companheiro. Conforme o argumento de João, a ausência de uma expectativa prévia que pudesse iniciar a construção de um preparo emocional está relacionada ao serviço escolhido.

A emoção desempenha um importante papel na dinâmica de negociação e aquisição dos serviços funerários, como pode ser apreendido das cenas acima descritas. Deslocando-a da esfera da psicologia individual para uma perspectiva que tem por premissa a sua construção social contextualizada, a emoção extrapola o indivíduo ao alcançar a vida social. Essa proposição passou a ecoar nos trabalhos antropológicos após a década de 1980, antes da qual a "ortodoxia psicológica" sobre emoção, isto é, pensá-la em termos de "processos psicobiológicos" que respondem a diferenças culturais, embora mantenham um núcleo, uma essência, inalcançável pelo social, era o padrão (Abu-Lughod \& Lutz 1990:2).

Segundo Lutz e Abu-Lughod, autoras que objetivam o entendimento da emoção enquanto relacionada à vida social e ao poder, há muitas formas em que ela "ganha sentido e força a partir de seu local e performance no domínio público do discurso" (1990:7, tradução nossa):

Preferencialmente, nós devemos ver o discurso emocional como uma forma de ação social que cria efeitos no mundo, efeitos que são lidos de maneira culturalmente informada pela audiência da conversa emocional. Emoção pode ser criada na, antes de moldada pela, fala (Abu-Lughod \& Lutz 1990:12, tradução nossa).

Fundamental ao circuito do mercado funerário é o entendimento de que a emoção é sempre uma presença pressuposta. Pressuposição esta responsável pelos termos em que os atendimentos e as negociações transcorrem. A emoção é performada pelo discurso dos profissionais, dos clientes e seus acompanhantes, estipulando, dessa maneira, uma negociação emocional que deve ser trabalhada no transcorrer do circuito. À negociações se associam elementos díspares, como os agentes fisicamente presentes na interação, cada qual atravessado por interesses particulares; a imposição da presença moral da pessoa morta; e a premência em escolher obrigatoriamente um serviço - cremação ou sepultamento - e produtos - com especial foco para as urnas. 
As condolências expressas pelos profissionais no início de cada atendimento, independentemente de sua correspondência com um sentimento "verdadeiro", têm por intenção transmitir o reconhecimento de um estado emocional pressuposto que o cliente estaria vivenciando. É o reconhecimento desse estado, construído por meio de um discurso emocional performado pelo profissional, que estabelece o vínculo necessário entre ele e o cliente. De outra forma, a ausência do reconhecimento transmitiria sensação de insensibilidade por parte do profissional para com o cliente, dinâmica em que a negociação econômica poderia ser vista como aproveitamento de um abalo emocional.

Não se trata de enquadrar o mercado funerário de Porto Alegre enquanto legalmente regrado e balizado por um comportamento alheio à extorsão. Enfatizamos, antes, a singularidade deste circuito, bem como o esforço empreendido para constituir um mercado supostamente moderno, compatível com outros segmentos. Não são gratuitas as seguidas referências que os agentes e os proprietários das funerárias fazem aos "outros" — isto é, sobretudo os estabelecimentos de "fora de Porto Alegre" — ou ao período "antes da Lei 373/1996". Mais do que um veredicto a respeito desse mercado, o que ressaltamos aqui é o esforço empreendido em prol de uma direção específica, contrária às representações estigmatizantes que o público em geral tende a fazer acerca deste segmento.

De fato, os agentes funerários têm plena consciência de que a susceptibilidade emocional dos familiares lhes favorece, mas esta certeza é contraposta por um projeto, mais amplo e duradouro, de transformar o mercado funerário em um "mercado sério". Este dilema é de algum modo experimentado pelos agentes em cada negociação - em algumas delas com mais intensidade do que em outras. O equilíbrio entre o interesse econômico dos vendedores e a susceptibilidade afetiva dos compradores parece demarcar um ideal a ser alcançado, sendo os agentes funerários treinados para criar um ambiente propício não apenas à negociação, mas a um certo estilo de negócio.

Há uma economia de linguagem, impregnada na retórica dos vendedores e no espaço das funerárias (conforme já destacado anteriormente), que visa à produção do que se poderia denominar de "acolhimento distanciado". A linguagem é direta, sucinta e clara, destinada a acolher, orientar e vender. É preciso demonstrar simpatia aos potenciais compradores, porém não de forma efusiva, na medida em que isto poderia sugerir que os agentes têm finalidades espúrias ao buscarem agradá-los ou, o que seria ainda pior, estarem verdadeiramente entusiasmados diante da possibilidade de realizar um ótimo negócio. Há que demonstrar consternação, mas nada além do que o protocolo sugere. 
Assim como outros profissionais da área médica que trabalham com situações-limite entre a vida e a morte, tal qual aqueles que se dedicam aos cuidados paliativos (Menezes 2004), os agentes funerários e outros profissionais, sobretudo os que manipulam diretamente os corpos, precisam adquirir uma dada sensibilidade visando, por um lado, evitar o envolvimento afetivo com os sujeitos e, por outro, não objetificá-los — o que seria uma das estratégias possíveis para escapar à primeira alternativa. Veremos, em seguida, que o humor pode ser uma dessas possibilidades, mas que há situações-limite, como no caso da morte de crianças e bebês.

Com a criação de um ambiente emocional explícito - e pressuposto - a partir da lógica de reconhecimento, as negociações passam a ocorrer. Sendo assim, a emoção atua em decorrência de uma gramática específica que busca legitimar o trabalho dos profissionais no estabelecimento de um vínculo com seus clientes, a partir do qual a negociação econômica é viabilizada. A emoção é capaz de "dramatizar, reforçar ou alterar as macrorrelações sociais que emolduram as relações interpessoais das quais emerge a experiência emocional individual", uma dinâmica sintetizada na forma de "micropolítica da emoção" (Coelho \& Rezende 2010:78).

A influência da emoção nas negociações performadas no interior deste circuito está em muitos lugares. Durante incursão a campo em um cemitério da região metropolitana de Porto Alegre, acompanhando a responsável pelo empreendimento, um cliente, junto de seus familiares, se aproximou dela. Seu interesse era saber por que eles não poderiam colocar fotografias dos seus pais na lápide deles se em outras havia. A responsável explicou que há diferentes modalidades de espaço no interior do empreendimento mas, caso desejassem, ela poderia explicar como funciona a transferência dos corpos para outro espaço em que a fotografia é autorizada e mostrar os preços referentes a essa mudança. "Mas e se colocarmos as fotografias?", questiona o cliente. "O seu contrato diz que isso não é autorizado", responde a responsável. Todos os familiares se olham e um lança a pergunta: "Vocês se lembram disso no contrato?", ao que todos imediatamente refutam e afirmam que "na hora ninguém leu o contrato direito por causa do estado emocional".

\section{A escolha da urna e as boas combinações}

"Em geral é por meio de coisas que realmente fazemos as pessoas", sintetiza Miller acerca da sua proposta questionadora à oposição comum entre pessoas e coisas no cotidiano social (2013:202). Sua proposta, alinhada a um contexto no qual recai certa instabilidade sobre oposições que demarcam os estatutos 
de pessoa e coisa, ou vida e morte, oferece subsídios para o esboço de novos contornos e problematizações ao quadro empírico observado. A síntese de Miller, embora mantenha a distinção entre os estatutos de "pessoa" e "coisa", propõe a redução da distância entre eles ao afirmar que coisas fazem pessoas. Em outras palavras, as coisas compõem as pessoas, mas também são as pessoas que escolhem as coisas. No presente contexto, a redução da distância simbólica entre "pessoa" e "coisa" defendida por Miller assume outras configurações no estatuto da pessoa coisificada: alguém despido dos direitos legais atribuídos às pessoas vivas — como a posse de propriedades e objetos - agenciada legalmente enquanto uma coisa e costumeiramente "preparada" nas dependências de funerárias com vistas ao alcance de uma naturalidade imaginada, mas que permanece capaz de influenciar decisões e integrar negociações ao longo desse processo. No curso de sua permanência no circuito do mercado funerário, é na etapa de escolha da urna, de seu invólucro, que a pessoa morta se faz mais presente e atuante.

A escolha da urna é um passo fundamental no atendimento funerário, pois sua venda deve ser realizada independentemente da escolha pelo sepultamento ou pela cremação e deve — assim como a remoção do corpo do local do óbito - constar na nota fiscal do serviço funerário. A urna é obrigatória em todos os casos de óbitos e destinação final. Qualquer produto extra é opcional. Ela cumpre, pois, tanto uma função prática de abrigar um corpo quanto simbólica, sendo uma espécie de vestimenta obrigatória do morto.

Há no espaço do mostruário uma lógica de distribuição espacial dos produtos com a finalidade de influenciar a escolha dos compradores. Em geral - e era este o caso nas duas funerárias observadas - as urnas são dispostas em ordem crescente de preço, embora a dinâmica de venda seja diferenciada entre as empresas. Na Funerária B, todas as urnas são identificadas com uma etiqueta na qual consta um nome em latim e um curto adágio a ele relacionado. Um vendedor, com catálogo em mãos, acompanha o cliente e informa o preço das urnas quando solicitado. Os preços não são visíveis ao cliente. Conforme elucida Luís, responsável pela empresa, os vendedores devem saber conciliar o poder aquisitivo do cliente e o momento emocional em que ele se encontra. Devem, assim, fazer a melhor venda dentro das limitações econômicas e emocionais do cliente e evitar, com isso, acusações de explorar um momento delicado.

A Funerária A, por seu turno, apresentou uma interessante atualização das práticas ao incluir nas urnas uma etiqueta com os preços, dispensando o auxílio do agente funerário para tanto. Se antes as vendas eram efetuadas de maneira similar à Funerária $B$, essa alteração influenciou diretamente na margem de negociação dos agentes funerários. Paulo, agente funerário, 
comenta que a mudança na forma de expor o preço foi sugerida pelo coordenador operacional como um experimento, pois ele acreditava que colocar os preços dos pacotes nas urnas aumentaria a transparência da negociação. Paulo reafirma, assim como o fez Luís a respeito da dinâmica na Funerária $B$, "que não se deve insistir, mas dá para notar qual o poder aquisitivo da família e trabalhar nesse registro".

A criação dos pacotes teve por intenção facilitar a exposição de preços e serviços oferecidos pela funerária e, simultaneamente, aumentar a transparência da sua atuação econômica na relação com os clientes — muito embora a amplitude entre os preços de compra e revenda permaneça uma informação distante destes. João quis "apostar na transparência dos serviços" ao deixar explícito "quanto o cliente está pagando de fato por cada item". Como fica evidente por meio da exposição das etiquetas que listam os serviços e os preços, não há variação nos itens véu, livro, lenço, remoção, tanatopraxia e documentação. A variação ocorre apenas na urna, nas coroas e nos mantos de flores e na decoração extra.

A experiência da Funerária A em ampliar a transparência em decorrência da exclusão de um mediador que detém os preços não foi unânime. Um dos profissionais manifestou discordância do sistema, apesar de ser "a favor da transparência". Segundo ele, expor os preços pode influenciar o cliente em momentos de dúvida entre urnas com preços similares. Nesses casos, em que haveria a possibilidade de o vendedor influir sobre a escolha, o comprador pode acabar por escolher uma urna "no meio-termo entre as outras". Dito de outro modo, expor o preço amplia a transparência porque reduz a margem de manobra do vendedor, limitando suas possibilidades de intervenção e influência nas decisões de consumo. Antes da mudança, os preços tinham variações bem mais expressivas. Perguntado sobre qual seria a urna mais cara do mostruário, João responde: “Qualquer uma, se bobear até essa", ao apontar para uma urna simples. "Depende da situação da família e de quem compra". João complementa seu argumento ao afirmar que uma das urnas dispostas, de cerejeira, já foi vendida por Marcelo por R\$ 80.000.

O fato de as funerárias pretenderem constituir um mercado transparente não significa que, à luz dos seus próprios interesses, as negociações não sejam qualificadas como "boas" ou "ruins". Na medida em que este circuito tem procurado se distanciar do estigmatizado mercado funerário, suas estratégias são reveladoras do que se imagina ser um mercado transparente, o qual parece pressupor um ideal de justiça impregnado ao contrato comercial, além de uma margem de manobra que deve ser acessível a ambas as partes envolvidas na negociação. Os detalhes etnográficos expõem um agenciamento construído pelas funerárias nesta direção, com o suporte direto 
ou indireto de consultores de marketing e vigiados pelo Estado - através da Lei municipal 373/1996.

Embora haja um espaço para a negociação, como atestam os preços diferenciados das urnas, os agentes funerários evitam, a todo o custo, o regateio. O regateio é uma prática recorrente e valorizada em certos mercados, sobretudo quando as negociações são pessoalizadas (Journet 2005; Stewart 1994). Nestes mercados, o regateio é parte indispensável da negociação, pois ele permite a realização de performances tanto por parte do comprador quanto do vendedor. O regateio pessoaliza a negociação, razão pela qual pode ser identificado em quase todos os mercados ditos tradicionais embora ele esteja presente também em alguns segmentos modernos. O mercado funerário seria propício a esta estratégia, dadas as variações de preços e as relações pessoalizadas. No entanto, o que fazem os agentes funerários quando os compradores insinuam o regateio? Eles o evitam. Ao invés de proporem descontos, oferecem produtos de menor valor - o que, à primeira vista, pode parecer uma modalidade de regateio utilizada pelas funerárias. Sem desconsiderar completamente tal interpretação, preferimos enfatizar esta estratégia de distanciamento do regateio convencional, pois ela retira do agente funerário a agência em relação ao preço dos produtos e, retirando esta agência, retira-se dele uma margem substantiva de influência na negociação. Ao viabilizar tal estratégia, as funerárias evitam que os agentes - em geral também comissionados — se deixem afetar por uma circunstância que os faça perder de vista a intencionalidade da empresa: a de constituir-se como parte de um mercado transparente.

A rigor, todas as urnas cumprem a mesma função prática, variando apenas no acabamento diferenciado, tipo de madeira e material ecológico. Mas a função prática, aqui, é acionada com maior frequência pelos "espíritos de orelha" e não por aqueles que de fato tomam — ou verbalizam, nas situações em que a vontade do morto é assentida - as decisões, em geral familiares próximos do falecido. Nas palavras do National Funeral Service Journal, "O foco do interesse do comprador deve ser a urna, o jazigo, a vestimenta, os carros funerários etc. - a única evidência tangível de quanto foi investido no funeral - o único verdadeiro símbolo de status associado ao serviço funeral" (Mitford 2000:35, tradução nossa). No momento em que o argumento em prol da função prática da urna termina por ser o definitivo, seja qual for o motivo, a venda tende a representar um "serviço ruim". Se uma venda de R\$ 23.000 é considerada um bom serviço, há igualmente um polo contrário dominado pelos serviços ruins - ou produtos de baixo custo — que são referidos como "querosene". Embora seja possível que funerárias com preços voltados às camadas mais abastadas façam serviços querosene, este termo também é empregado 
para adjetivar funerárias específicas que trabalham com camadas populares. "Querosene" é um serviço barato ou uma funerária que costuma realizá-los.

Conforme expresso no Art. $3^{\circ}$ da Lei 373/1996, "os serviços funerários de comercialização de urnas funerárias terão tipos e padrões aprovados pela Administração Municipal, sendo equivalentes para todas as funerárias". Com isto em vista, há em todas as funerárias a obrigatoriedade de oferecimento do "padrão prefeitura", ${ }^{17}$ o que possibilita serviços "querosene" em funerárias voltadas a um público com maior poder aquisitivo. Todavia, há estratégias para evitar a realização de serviços "querosene" ou, ao menos, para separá-los dos demais. A Funerária B, voltada para um público com alto poder aquisitivo, possui em sua sede dois ambientes de mostruário: um, localizado no andar superior, em uma elegante sala com sofás para descanso, e outro, no subsolo, onde as urnas mais simples, dentre elas as que compõem o "padrão prefeitura", compartilham um espaço modesto ao lado de uma escada. Seja para os serviços bons ou para aqueles classificados como querosene, a venda da urna é a principal escolha no processo de negociação entre profissional e cliente, pois representa a definição do espaço no qual o corpo morto, recém-preparado, será acondicionado e apresentado para o velório.

Como ilustrado anteriormente, há negociações possíveis de serem efetivadas entre agente funerário, pessoa morta e responsável. Há casos, no entanto, em que não existe nem mesmo negócio. Todas as empresas funerárias de Porto Alegre são obrigadas, pelos termos da permissão pública, a funcionar ininterruptamente e devem ter um espaço no qual seus funcionários possam repousar durante a noite. Na Funerária A, esse espaço é uma pequena sala de descanso onde dois sofás ficam à disposição dos funcionários. Em certa ocasião, o telefone tocou no meio da noite. Tratava-se de um natimorto. O agente, ao atender o telefonema, convidou os familiares a comparecer na funerária para dar prosseguimento ao serviço. Em meio à madrugada, cinco pessoas chegaram para organizar os preparativos, um número consideravelmente alto, acima da média dos atendimentos acompanhados ao longo da etnografia. Uma vez solicitada a Declaração de Óbito e os dados filiais do natimorto, ${ }^{18}$ o agente funerário apresentou aos familiares a urna em que ocorreria o sepultamento - pequena, toda branca se não fosse pelas alças douradas. Com a aprovação da família e do responsável, eles passaram então a definir o local do sepultamento. Por opção dos familiares presentes, não haveria velório, somente uma rápida cerimônia religiosa.

Por política da empresa, explicou o agente funerário à família do natimorto, não haveria cobrança pelos serviços da funerária nem pela urna, que seria registrada internamente enquanto doação. Conversando posteriormente com João, ele explicou que a Funerária A definiu a isenção de 
cobrança quando o serviço é para alguém de até 3 anos de idade. Decisão de cunho pessoal, João conta que viu seu filho convulsionar quando pequeno e ficou muito abalado: "Não conseguiria cobrar nessas situações", conclui o coordenador operacional da funerária. Posição similar é descrita por Lynch, diretor funerário em Milford, Estados Unidos: “E eu jamais cobraria mais do que o preço de atacado da urna e colocaria nossos serviços sem custo com a esperança no meu coração de que Deus, em retorno, me pouparia da dor dilacerante desses pais" (1997:52, tradução nossa).

Há uma razão econômica que viabiliza a gratuidade dos serviços no caso de óbitos infantis, seja porque são óbitos raros nesse contexto, ou porque as cerimônias requisitadas são menos dispendiosas - como no caso do natimorto. Porém há também razões de outra ordem: o óbito infantil não permite que as empresas funerárias mantenham a negociação na fronteira desejada. Mesmo no âmbito dos empreendimentos de destinação final, tais óbitos são tratados como casos "delicados". Nestes casos, os funcionários com filhos pequenos são dispensados da realização dos serviços. André comenta que, apesar de não ser possível o envolvimento emocional dos funcionários com todos os casos e famílias, sob o risco de inviabilizar o trabalho, quando há falecimento de crianças, há também maior comoção entre os funcionários. É em razão desse envolvimento, dessa constante provação emocional, que a empresa oferece apoio psicológico aos seus funcionários.

“No cotidiano, as pessoas investem esforços intensos e preocupações constantes para encontrar a combinação correta entre as relações econômicas e os laços íntimos" (2011:14), escreve Zelizer como resposta à percepção de senso comum acerca da incompatibilidade entre territórios da intimidade e da economia. Embora ao longo de sua arguição a autora foque na incidência de questões econômicas no interior de laços de intimidade, sua argumentação pode ser transposta para o domínio das interações entre questões econômicas e emocionais. Ainda conforme Zelizer,

[...] ela [a intimidade] é tão importante para os seus participantes e terceiros que as pessoas constantemente traçam limites morais entre os usos próprios e impróprios dela. Sim, a intimidade comporta um ônus moral, mas exatamente porque tipos diferentes de intimidade variam em suas qualidades morais (2011:25).

Se nos primeiros casos aqui relatados ficou evidente a busca de um equilíbrio entre o econômico e o emocional, em outros esta combinação parece inviável, como o caso do natimorto. Conforme expressa o coordenador operacional em sua fala sobre este atendimento, é a percepção de uma situação emocionalmente extrema ou sobremaneira delicada que impede a 
abordagem dos aspectos econômicos próprios de uma empresa funerária. Conquanto o natimorto fosse um óbito tecnicamente comerciável — pois assumido por uma empresa local — ele não foi um óbito negociável: diante da impossibilidade de alcance de uma boa combinação entre emocional e econômico e, por consequência, da impossibilidade de condução de qualquer modalidade de negociação, todos os preços referentes à atuação da funerária foram excluídos da interação com o cliente, a quem coube apenas expor suas preferências a respeito do local de sepultamento.

\section{Conclusão}

Um truísmo no domínio das relações comerciais, a interação entre agente funerário e cliente é baseada em negociação. Contudo, no caso do circuito analisado, à equação são adicionadas outras variáveis que tornam a negociação de consumo sobremaneira complexa. Se as empresas e os profissionais que atuam no circuito do mercado funerário agem na fabricação da pessoa morta por meio do seu "preparo" físico e, subsequentemente, pela elaboração de um conjunto de lembranças a ela relacionadas, ${ }^{19}$ é a presença dessa mesma pessoa a variável sui generis nesta dinâmica. A atuação das agências funerárias, em que pese uma série de restrições ao consumo, busca alternativas para expandir a oferta de produtos e serviços. Neste sentido, o mercado funerário performa a morte a tal ponto que acaba contribuindo para o processo de construção de uma nova pessoa - a "pessoa morta". Investimentos estéticos visando afastar, tanto quanto possível, a pessoa morta da ideia de morte não são novidade se pensarmos nas tradições de longa duração. Todavia, a realização deste empreendimento mediado pelo mercado, como vimos aqui, talvez seja algo singular, ao mesmo tempo um produto e uma produção da laicidade. ${ }^{20}$

O presente artigo teve por intenção abrir as portas a um mercado pouco conhecido do grande público, elencando as etapas de negociação e consumo que transcorrem em seu interior. O circuito do mercado funerário, trajeto no qual atos de consumo estão mais presentes, envolve negociação, e esta pressupõe diferentes participantes, dentre eles a própria pessoa morta, através de sua memória e presença moral. Enquanto uma economia emocional, a pressuposição de um estado emotivo é fundamental como um dos mecanismos de precificação dos bens e serviços oferecidos pelas funerárias, em uma lógica segundo a qual valores e emoções são negociados. A pressuposição e o subsequente reconhecimento do estado emocional, interação performada - ou construída - pelos consumidores e pelos profissionais, 
influenciam os serviços e os produtos escolhidos e os preços por eles cobrados. Conquanto possa elevar os preços em determinadas situações, também age no sentido oposto ao diminuí-los ou, inclusive, anulá-los por completo, como foi o caso do natimorto.

Faz-se fundamental no presente caso refutar qualquer tendência a solidificar duas esferas reificadas circunscritas, uma ao domínio da economia, e outra ao das emoções. No âmbito do circuito analisado, economia e emoção interagem mutuamente em todas as etapas, tais como: precificação, negociação entre profissional e cliente, escolha de custo benefício etc., o que não significa dizer que não haja tensão. O esmaecimento das fronteiras, pelo menos no plano interpretativo, constitui, assim, um todo orgânico no qual à economia é fundamental o trabalho exercido pelas emoções, sendo o inverso igualmente válido. Um todo orgânico estabilizado sob a alcunha de economia emocional.

Recebido em 21 de maio de 2015

Aprovado em 17 de fevereiro de 2016

Marcos Freire de Andrade Neves é doutorando em Antropologia Social no PPGAS/ UFRGS. E-mail: <marcosfan@gmail.com>.

Arlei Sander Damo é professor do PPGAS/UFRGS. E-mail: <arleidamo@uol. com.br>

\section{Notas}

${ }^{1}$ Uma descrição acerca do complexo funerário como um todo, ou seja, de seus diferentes circuitos burocráticos, de mercados e legais, pode ser encontrada em outro espaço (Andrade Neves 2014). O complexo funerário, por meio de seus diferentes circuitos, age na produção de um estatuto específico para a pessoa morta, envolvendo não somente aspectos legais e burocráticos, mas também o preparo físico do corpo através de técnicas como tanatopraxia e massagem corporal, cujo intuito é a busca por uma "naturalidade" na aparência do corpo para a sua apresentação durante o velório. O presente artigo tem o complexo funerário apenas como pano de fundo, pois foca a sua argumentação em um de seus circuitos componentes: o circuito do mercado funerário. É este circuito, em conjunto com outros que não serão aqui descritos, que performa o chamado complexo funerário, algo mais amplo que vai além de questões de negociação e mercado, foco deste artigo. 
${ }^{2} \mathrm{O}$ presente artigo é resultado de pesquisa etnográfica conduzida no período entre 2012 e 2013. A referida pesquisa serviu como base para a escrita da dissertação intitulada "Por onde vivem os mortos: o processo de fabricação da morte e da pessoa morta no segmento funerário de Porto Alegre" (Andrade Neves 2014). Embora o presente texto tenha relação com a dissertação, sua produção exigiu uma releitura do trabalho original, em um esforço de síntese etnográfica e adequação teórica. A pesquisa original contou com financiamento da Coordenação de Aperfeiçoamento de Pessoal de Nível Superior (Capes).

${ }^{3}$ Constituição Federal de 1988, Art. 30, incisos I e V.

${ }^{4}$ Conforme informações disponibilizadas pela Prefeitura de São Paulo no endereço: <http://www.prefeitura.sp.gov.br/cidade/secretarias/servicos/servico_funerario/ organizacao/estrutura/index.php?p=3528> Acesso em fevereiro de 2015.

${ }^{5}$ No caso de Zelizer (2005), a noção foi particularmente utilizada para descrever diferentes modalidades de mercados no âmbito do capitalismo, contrapondo a ideia de um sistema mundialmente articulado de forma hegemônica e homogênea. Um dos objetivos do conceito é destacar as múltiplas possibilidades de trocas com interfaces distintas em relação ao que se considera como "o" mercado. A noção também se presta como um recurso estenográfico que auxilia o pesquisador a circunscrever um determinado percurso de pessoas e coisas, com ênfase nos fluxos e não nas instituições.

${ }^{6}$ No caso dos cadáveres destinados à pesquisa, eles recebem um tratamento muito próximo à doação de órgãos (Steiner 2010). São tratados como um tipo de commodity, matéria-prima essencial e seguidamente escassa no treinamento de estudantes das áreas médicas. Esses corpos têm um valor econômico, em que pese o fato de muitas legislações tratarem de sublimar este valor, impedindo a criação de um mercado convencional. Como evidenciado por Andrade Neves (2016, no prelo), os cadáveres destinados pelo DML de Porto Alegre às universidades eram objeto de uma economia de escambo, sendo trocados por serviços.

${ }^{7}$ A literatura socioantropológica sobre o uso da noção de performance a partir de Callon é extensa e não poderia ser aqui detalhada. Nossas principais referências a respeito incluem, entre outras: Muniesa e Callon (2010); Callon (2013a, 2013b); Mackenzie e Millo (2003).

${ }^{8}$ Ver, dentre outros trabalhos mais recentes, Bevilaqua (2010); Carvalho (2007); Lock (2002, 1996); Macedo (2012); Medeiros (2012); Menezes (2004); Norwood (2007, 2009); Pool (2004); Rodrigues (2006).

${ }^{9}$ Todos os nomes aqui apresentados são pseudônimos. Por sua vez, os nomes das empresas foram substituídos por letras - Funerária A, Funerária B etc.

${ }^{10}$ Tanatopraxia é um procedimento não obrigatório na maioria de casos de óbito, porém contratado com alta frequência, que envolve a infusão de químicos para preservar a coloração do corpo e melhorar a sua preservação. 
${ }^{11}$ Esta lei buscou alterar o funcionamento do complexo funerário na cidade, impondo novas normas, obrigações e instâncias fiscalizadoras. A lei é por vezes referida como um ponto de inflexão na atuação das empresas funerárias dentro do município e teve por intenção "profissionalizar" o serviço e romper com uma imagem negativa associada ao trabalho na área. Ela prescreve não somente como deve ser realizado o atendimento, como também impõe normas aos espaços físicos das empresas.

${ }^{12} \mathrm{Ou}$ "preparadores", termo utilizado para indicar os profissionais que realizam a tanatopraxia, maquiagem e vestimenta da pessoa morta.

${ }^{13}$ O título da seção é uma referência ao artigo de Gell, "Recém-chegados ao mundo dos bens: o consumo entre os Gonde Muria".

${ }^{14}$ Em seu trabalho, Campbell parte de um questionamento acerca da posição social ocupada pelo consumo. Uma questão fundamentalmente semelhante aparece, é claro, em relação ao problema de explicar o consumismo moderno: como poderia uma atividade - neste caso, a procura pelo prazer - que era, no máximo, eticamente tolerada converter-se no aceitável objetivo de vida dos cidadãos da sociedade contemporânea (2001:145).

${ }^{15}$ À diferença de outras modalidades de aquisições, que tendem a ser celebradas socialmente com certo alarido (no caso de automóveis, imóveis ou mesmo de vestuário), aquelas atinentes ao mercado funerário tendem a ser avaliadas discretamente. A etiqueta recomenda contenção nestes casos, pois as aquisições devem parecer indesejáveis e expressadas publicamente neste registro. Um familiar que realizou as negociações pode experimentar a sensação de "dever cumprido" e até receber elogios nesta direção, mas este parece ser o limiar moral do reconhecimento. Mais do que isso poderia sugerir um estado de satisfação que contraria as expectativas para a ocasião, conforme já assinalou Mauss (1979) na discussão sobre a "expressão obrigatória dos sentimentos". Há casos nos quais o consumo de bens e serviços funerários é claramente conspícuo, mas eles não constituem a regra e precisariam ser analisados com mais profundidade em outro momento.

16 "As singularidades são produtos comerciais (bens e serviços) incomensuráveis. E o mercado de singularidades é composto de relações marcadas pela incerteza sobre a qualidade entre os produtos singulares e os atores em busca da 'boa' singularidade" (Karpik 2007:38). Nesta mesma linha e usando a noção de "economia das qualidades" são os argumentos de Callon, Méadel e Rabeharisoa (2013), incluindo-se uma apreciação pontual sobre o conceito de "economia das singularidades" (:152-7).

${ }^{17}$ Art. $3^{\circ} \S 1^{\circ}$ - Os padrões para serviço funerário, obrigatórios para todas as empresas funerárias, serão em número mínimo de dois: a) padrão I, simples; b) padrão II, especial.

${ }^{18}$ De acordo com Resolução CFM n 1.779/2005, “Em caso de morte fetal, os médicos que prestaram assistência à mãe ficam obrigados a fornecer a Declaração 
de Óbito quando a gestação tiver duração igual ou superior a 20 semanas ou o feto tiver peso corporal igual ou superior a 500 (quinhentos) gramas e/ou estatura igual ou superior a $25 \mathrm{~cm} "$.

${ }^{19}$ Através de serviços específicos que podem ser contratados nos empreendimentos de destinação final, como cemitérios e crematórios, e envolvem a realização de cerimoniais para homenagear a pessoa morta.

${ }^{20}$ Embora não tenhamos tido espaço para discutir aqui, o contexto etnografado mostrou a oferta de certos rituais religiosos (católicos, sobretudo) como "serviços opcionais", numa clara relação de englobamento do religioso pelo mercado.

\section{Referências bibliográficas}

ABU-LUGHOD, Lila \& LUTZ, Catherine A. 1990. Language and the politics of emotion. Cambridge: Cambridge University Press.

ANDRADE NEVES, Marcos. 2014. Por onde vivem os mortos: o processo de fabricação da morte e da pessoa morta no segmento funerário de Porto Alegre. Dissertação de Mestrado, Programa de Pós-Graduação em Antropologia Social, Universidade Federal do Rio Grande do Sul (PPGAS/UFRGS). - 2016. Entre pessoa, corpo e coisa: a vida social de cadáveres em laboratórios de anatomia. No prelo.

BARTHES, Roland. 1984. A câmara clara. Rio de Janeiro: Editora Nova Fronteira. BEVILAQUA, Ciméa. 2010. "Sobre a fabricação contextual de pessoas e coisas: as técnicas jurídicas e o estatuto do ser humano após a morte". Mana. Estudos de Antropologia Social, 16(1):7-29.

CALlON, Michael. 2013a. "Qu'est-ce qu'un agencement marchand?". In: Michael Callon et al. (eds.), Sociologie des agencements marchands. Paris: Mines-ParisTech. pp. 325-440.
_ 2013b. "La formulation marchande des biens". In: François Vatin (org.), Évaluer et valosiser-une sociologie économique de la mesure. 2. ed. Toulouse: Presses Universitaires du Mirail. pp. 263-285. - 2006. What does it mean to say that economics is performative? CSI Working Papers Series 005. Disponível em: https://halshs.archives-ouvertes.fr/halshs-00091596. Acesso em março de 2015. . 1998. The laws of the markets. London: Blackwell.

CALLON, Michael, MÉADEL, Cécile \& RABEHARISOA, Vololona. 2013. "L'économie des qualités". In: Michael Callon et al. (eds.), Sociologie des agencements marchands. Paris: Mines-ParisTech. pp. 143-70.

CAMPBELL, Colin. 2001. A ética romântica e o espírito do consumismo moderno. Rio de Janeiro: Rocco.

CARVALHO, Letícia. 2007. Dos autos da cova rasa: a identificação de corpos não identificados no Instituto Médico-Legal do Rio de Janeiro, 1942-1960. Rio de Janeiro, Programa de Pós-Graduação em Antropologia Social, 
Museu Nacional, Universidade Federal do Rio de Janeiro.

COELHO, Maria Claudia \& REZENDE, Claudia Barcellos. 2010. Antropologia das emoções. Rio de Janeiro: Editora da FGV. DOUGLAS, Mary \& ISHERWOOD, Baron. 2009. O mundo dos bens: para uma antropologia do consumo. Rio de Janeiro: Editora UFRJ.

FASSIN, Didier. 2012. A companion to moral anthropology. London: John Wiley \& Sons, Inc.

JOURNET, Nicolas. 2005. "L'argent en famille". Terrain, 45:5-12.

LOCK, Margaret. 2002. Twice dead: organ transplants and the reinvention of death. Berkeley and Los Angeles: University of California Press. . 1996. "Death in technological time: locating the end of meaningful life". Medical Anthropology Quarterly, 10(4): 575-600.

KARPIK, Lucien. 2007. L'économie des singularités. Paris: Gallimard.

LYNCH, Thomas. 1997. The undertaking: life studies from the dismal trade. Nova York: W. W. Norton \& Company. MACEDO, Juliana Lopes de. 2012. Quando a vida encontra a morte: as concepções médicas e jurídicas sobre anencefalia e morte encefálica. Porto Alegre: UFRGS/ PPGAS.

MACKENZIE, Donald; MILLO, Yuval. 2003. "Constructing a market, performing theory: the historical sociology of a financial derivatives exchange." American Journal of Sociology, 109(1):107-45.

MAUSS, Marcel. 1979. "A expressão obrigatória de sentimentos". In: Roberto Cardoso de Oliveira (org.), Marcel Mauss. Col. Grandes Cientistas Sociais. São Paulo: Ática. pp. 147-53.

MEDEIROS, Flavia. 2012. "Matar o morto": A construção institucional de mortos no Instituto Médico-Legal do Rio de Janeiro. Dissertação de Mestrado, Programa de Pós-Graduação em Antropologia,
Instituto de Ciências Humanas e Filosofia, Universidade Federal Fluminense. MENEZES, Rachel Aisengart. 2004. Em busca da morte: antropologia dos cuidados paliativos. Rio de Janeiro: Garamond/ Fiocruz.

MILLER, Daniel. 2013. Trecos, troços e coisas: estudos antropológicos sobre a cultura material. Rio de Janeiro: Zahar.

MITFORD, Jessica. 2000. The American way of death revisited. Nova York: Vintage Books.

MUNIESA, Fabian; CALLON, Michel. 2010. "La performativité des sciences économiques". In: Philippe Steiner, François Vatin (orgs.), Traité de sociologie économique. Paris:Quadrige/ PUF. pp. 289-334.

NORWOOD, Frances. 2009. The maintenance of life: preventing social death through euthanasia talk and end-of-life care - lessons from the Netherlands. Durham: Carolina Academic Press. .2007. "Nothing more to do: euthanasia, general practice, and end-of-life discourse in the Netherlands". Medical Anthropology, 26(2):139-174.

POOL, R. 2004. "'You're not going to dehydrate mom, are you?': Euthanasia, versterving, and good death in the Netherlands". Social Science \& Medicine, 58(5):955-66.

RODRIGUES, José Carlos. 2006. Tabu da morte. Rio de Janeiro: Editora Fiocruz. STEINER, Philippe. 2010. "La merchadisation de l'humain et de la personne". In: Philippe Steiner \& François Vatin (orgs.), Traité de sociologie économique. Paris: Quadrige/PUF. pp. 493-530.

STEWART Michael. 1994. "La passion de l'argent. Les ambiguïtés de la circulation monétaire chez les Tsiganes hongrois". Terrain, 23:45-62.

THOMAS, Louis-Vincent. 1983. La antropología de la muerte. México: Fondo de Cultura Económica. 
ZELIZER, Viviana. 2011. A negociação da intimidade. Petrópolis: Vozes.

2005. "Circuits within capitalism". In: Victor Nee (ed.), The economic sociology of capitalism. Princeton: Princeton University Press. pp. 289-321. WEBSTER, Robert. 2011. Does this mean you'll see me naked?: field notes from a funeral director. Naperville: Sourcebooks. 


\section{Resumo}

Conduzida na cidade de Porto Alegre, Brasil, a pesquisa etnográfica aqui apresentada descreve circuitos que performam o chamado mercado funerário. Composto principalmente por funerárias, cemitérios e crematórios, o mercado funerário integra um complexo mais amplo cujo intuito é a criação de um estatuto da pessoa morta. Fundamental a este mercado, as negociações entre profissionais do ramo e clientes acabam por performar a agência da pessoa morta, uma das especificidades desta dinâmica de precificação. A pessoa morta, não sendo um locus de passividade, mostra a sua vida ao impor padrões de comportamento nas negociações concernentes ao seu funeral, assim como ao influenciar escolhas e decisões. A pesquisa concentra seu foco em funerárias de Porto Alegre, a partir das quais analisa ideias de uma economia emocional e das singularidades, a agência dos envolvidos nas negociação de consumo - vivos e mortos - e lógicas de precificação.

Palavras-chave Agência, Economia emocional, Mercado funerário, Negociação, Pessoa morta.

\section{Abstract}

This article describes the circuits of the so-called funeral industry in the city of Porto Alegre. Composed mainly of funeral homes, cemeteries and crematories, the funeral industry is part of a wider complex that aims to create a statute for the deceased. Negotiations between professionals and customers enact the dead person's agency, which is one of the specific characteristics of the dynamics of price setting. The dead person, not being a locus of passivity, establishes behavioural guidelines concerning his or her funeral arrangements, influencing choices and decisions, thereby exhibiting his or her life. The research focuses on funeral homes in Porto Alegre, through which we analyse the economies of emotions and singularities, as well as the agency of those involved in negotiations (both living and dead) and the logics of price setting.

Key words Agency, Emotional economy, Funeral Industry, Negotiation, The Dead. 